\title{
Analyst
}

CORRECTION

View Article Online

View Journal I View Issue

\section{Correction: Towards improved precision in the quantification of surface-enhanced Raman scattering (SERS) enhancement factors: a renewed approach}

Cite this: Analyst, 2015, 140, 670

Arumugam Sivanesan, ${ }^{\text {ab }}$ Witold Adamkiewicz, ${ }^{a}$ Govindasamy Kalaivani, ${ }^{\text {b }}$ Agnieszka Kamińska, ${ }^{\text {*a }}$ Jacek Waluk, $^{a}$ Robert Hołyst ${ }^{a}$ and Emad L. Izake ${ }^{b}$

DOI: $10.1039 / c 4 a n 90100 b$

Correction for 'Towards improved precision in the quantification of surface-enhanced Raman scattering (SERS) enhancement factors: a renewed approach' by Arumugam Sivanesan et al., Analyst, 2015, DOI:

www.rsc.org/analyst 10.1039/c4an01778a.

Regarding Fig. 1-3, the following should appear in the Acknowledgements section:

Figures and excerpt reprinted from Electrochemistry Communications, A. Sivanesan, W. Adamkiewicz, G. Kalaivani, A. Kamińska, J. Waluk, R. Hołyst and E. L. Izake 'Electrochemical pathway for the quantification of SERS enhancement factor', 2014, 49, 103-106, with permission from Elsevier.

The Royal Society of Chemistry apologises for these errors and any consequent inconvenience to authors and readers. 